\title{
Nonconformity tracking and prioritisation matrix: an approach for selecting nonconformities as a contribution to the field of TQM
}

\section{Michael Donauer, Paulo Peças \& A.L. Azevedo}

To cite this article: Michael Donauer, Paulo Peças \& A.L. Azevedo (2015) Nonconformity tracking and prioritisation matrix: an approach for selecting nonconformities as a contribution to the field of TQM, Production Planning \& Control, 26:2, 131-149, DOI: 10.1080/09537287.2013.867377

To link to this article: https://doi.org/10.1080/09537287.2013.867377

Submit your article to this journal $[\pi$

Џ Article views: 155

Q View related articles $\sqsubset$

View Crossmark data $\asymp$

Citing articles: 2 View citing articles 


\title{
Nonconformity tracking and prioritisation matrix: an approach for selecting nonconformities as a contribution to the field of TQM
}

\author{
Michael Donauer ${ }^{\mathrm{a}, \mathrm{b}}$, Paulo Peças ${ }^{\mathrm{c}}$ and A.L. Azevedo ${ }^{\mathrm{a}, \mathrm{b} *}$ \\ ${ }^{a}$ INESC TEC (formerly Inesc Porto), Porto, Portugal; ${ }^{b}$ Faculdade de Engenharia, Universidade do Porto, Rua Dr. Roberto Frias, \\ Porto, 4200-465, Portugal; ' ${ }^{2}$ DDEC, Instituto Superior Técnico, Technical University of Lisbon, Av. Rovisco Pais, Lisbon, 1049-001, \\ Portugal
}

(Received 21 June 2013; accepted 7 November 2013)

\begin{abstract}
Selecting quality improvement projects among a variety of mutually competing ones is characterised by prioritisation. In practice, this is often done by the rule of thumb, following a single attribute criterion or by subjective preferences of individual stakeholders of a project team. An approach to track systematically nonconformities and to identify those critical ones that should be prioritised based on multi-attribute criteria is presented. The approach is introduced and its purpose is explained. After the background of relevant topics is given, the method's importance in research and for practitioners is derived. Steps of the approach are portrayed and an application case of a mature industrial company, integrated in the supply-chain of the automotive industry, is presented. Elements of quality tools and techniques are used as attributes, namely failure mode and effect analysis and Pareto diagram. Results based on industrial data indicate that the use of this approach contributes to support informed and structured prioritisation decisions, which foster a more efficient improvement of future quality-based projects.
\end{abstract}

Keywords: multi-attribute decision-making; nonconformities; quality improvement projects; quality tool; TQM

\section{Introduction}

Targeting zero defects in production is an often sought state in any company but more crucial for the ones aiming to achieve world class manufacturing performance. While theoretically claimed, it is very demanding to establish into practice. This is owing to variability in production and to imprecise measures of testing and inspection equipment, among other minor sources of deviations from target. Ambiguity of the existence of an economical quality level characterises discussions around cost of quality $(\mathrm{CoQ})$ models. Notional CoQ models support both, the modern and the classic view, as explained in CoQ reviews (Plunkett and Dale 1987; Schiffauerova and Thomson 2006). According to the classic view the economic optimal point is positioned prior to perfect quality, because efforts to achieve zero defects are beyond price. The modern view on the other hand assumes that the cost of image loss through delivering nonconforming quality is tremendous and therefore the optimal economical point is only reached with zero defects (Freiesleben 2004).

Quality is a term with various definitions. In the realm of quality, a nonconformity ( $\mathrm{NC}$ ) is the nonfulfillment of a specified requirement (ANSI/ISO/ASQC A3534 1993). Deming (1986) recommends deriving from customer needs measurable characteristics to design the product in such a way that the customer receives satisfaction for paying a certain price. Thus, by translating customer requirements into attributes and impart those with metrics, quality becomes quantifiable and the product can be assessed against meeting metrics. A product that does not meet one of those metrics is nonconforming. Recording the occurrences yields a list of NCs that can range from visual, in terms of aesthetics or constructional, in terms of functions. Up to a certain threshold of not meeting a conforming metric products are recoverable through rework efforts. The others are scrapped or put to salvage. An NC list can be plentiful and NCs can occur at different spots at the product or multiple NCs can be identified for one product. Each single NC may be caused by different sources.

NCs can be detected prior to shipment at an inspection stage, or customers may claim and return the product if testing fails. Nonconforming products can cause inestimable damage when revealed to the customer. Losing future business with individual consumers is obviously less disastrous than having a commercial customer switching to competitors. Reducing the number of delivered nonconforming products can either be achieved (1) by reducing the occurring number of NCs through improved quality at the manufacturing process or (2) by increasing the efficiency of the inspection process. Both

\footnotetext{
*Corresponding author. Email: ala@fe.up.pt 
cases imply costs. In the first case, one has to invest in improving the manufacturing process and in the second case expenditures in tightening the detection of the inspection process take effect. Within the dimension of product and process quality it is thought that applying the spirit of 'do it right the first time' is less costly than maintaining a final inspection (Juran and Godfrey 1999). Thus, reducing production losses through continuously improving processes is aspired.

One lever to continuously ameliorate processes is to focus on a specific NC and to identify and eliminate its root causes. Among all NCs that are found, the selection and prioritisation of the right ones is key for improving quality efficiently. This is due to limited resources for investigation and rectification of the problem and to take multiple objectives into consideration. Within the total quality management (TQM) realm suggestions are provided on how to investigate root causes of NCs and on how to prioritise NCs as well. However, there is no published approach based on multi-attribute criteria to monitor, prioritise and select $\mathrm{NCs}$ for further investigation upon taking into consideration multi-attributes.

This study intends to fill this gap by presenting a novel approach to track and prioritise NCs with weighted multi-attributes. This approach promotes selective tracking among a set of NCs fostering its prioritisation for the selection of future improvement projects. The approach has a multi-attributes weighting engine based on failure mode and effect analysis (FMEA) and Pareto principles. This research is a contribution to existing quality tools in the TQM literature. Results indicate that the approach presented in this study can be used by practitioners such as quality engineers but can also be applied for any portfolio prioritisation problem.

A literature review of relevant topics is given and the approach for prioritising NCs is presented. After illustrating the proposed notional model, instructions for devising the approach is provided and a real-based data case study from the automotive industry is presented. In addition, a complementary presentation of $\mathrm{NC}$ is introduced to enhance the understanding of its profile according to quality-related attributes. Results are shown, discussed and conclusions drawn.

\section{Background and research development}

This section frames the theoretical background on TQM, FMEA and quality tools as its relation with the approach proposed. Furthermore, the research aims and scope are discussed.

\subsection{The use of tools in quality}

TQM is often described as a philosophy equipped with a set of tools and a set of guidelines that form the basis for continuous and gradual quality improvement of the total organisation. The target is to increase customer satisfaction and continuous improvement of products and processes. Satisfying the needs of the internal customer through tactics for changing a company's culture and some structured technical techniques are central elements (Rampey and Roberts 1992; Hradesky 1995). However, there is no global definition for TQM and companies often show high variation regarding its interpretation and level of implementation (Bounds 1994; Lakhe and Mohanty 1994). TQM is also understood as a management system consisting of values, techniques and tools, as three interdependent components (Hellsten and Klefsjö 2000). In literature, the tools of TQM have evolved, however, the seven quality control tools, firstly selected by Ishikawa (1976), are still generally accepted (Table 1). After Ishikawa's seven tools, a new set of seven management tools was presented, which are more related to process mapping and problem-solving (Mizuno 1988).

Many of the basic tools today were developed by a handful of people - Shewhart (1931), Deming (2000), Juran and Gyrna (1980), Ishikawa (1990), Ōno (1988), Shingō (1986) and Taguchi (1986) - starting in the late 1930s. What evolved since that time is our ability for using the tools together programmatically to achieve company wide benefits (Beckman and Rosenfield 2007).

Table 1. Quality tools and techniques used in industry (Dale and McQuater 1998).

\begin{tabular}{llll}
\hline The seven basic quality control tools & The seven management tools & Other tools & Techniques \\
\hline Cause and effect diagram & Affinity diagram & Brainstorming & Benchmarking \\
Check sheet & Arrow diagram & Control plan & Department purpose analysis \\
Control chart & Matrix diagram & Flow chart & Design of experiments \\
Graphs & Matrix data analysis method & Force field analysis & Fault tree analysis \\
Histogram & Process decission program chart & Questionnaire & FMEA \\
Pareto diagram & Relations diagram & Sampling & Poka yoke \\
Scatter diagram & Systematic diagram & & Problem solving methodology \\
& & & Quality costing \\
& & & Quality function deployment \\
& & & Quality improvement teams \\
& & Statistical process control \\
\hline
\end{tabular}


As the 'old' TQM tools were more focused on shop floor visual quality assessment and control the 'new' TQM tools are more focused on offline quality monitoring, action planning and complex problem depicting. Besides those rather direct production management tools, the TQM philosophy inspired the development of more sophisticated approaches dedicated to main cause searching, intricate correlations finding, variability controlling and multi-attribute process optimisation.

The most widely used tools and techniques are summarised by Dale and McQuater (1998) and depicted in Table 1. McQuater et al. (1995) distinguish a tool, as a gadget with a defined function, from a technique, whose range of use is broader and can be composed of different tools. Ahmed and Hassan (2003) conclude that quality management is supported by the use of suitable tools. Moreover, they identify that a greater implementation of quality management tools results in a better firm performance than a lower implementation.

One item listed in Table 1 is FMEA. In the automotive industry, FMEA is adapted and applied as a quality improvement tool and often as part of an installed quality system (McDermott, Mikulak, and Beauregard 1996). McDermott, Mikulak, and Beauregard (1996) state that the use of FMEA contributes to its cost reduction. This can be achieved in both stages, the development and manufacturing stage, by the identification of product and process improvements with the goal to avoid corrective action and late changes (McDermott, Mikulak, and Beauregard 1996). Hereby, the relative risk of a specific failure is evaluated and attributed with a risk priority number which is composed by three attributes: severity (consequence of failure if occurs), occurrence (frequency of occurring failure) and detection (probability of failure detection). This yields a ranked list of failures with priority numbers, of which the highest shall be given priority to.

The tools and techniques presented in Table 1 are basically the same as the ones used widely by occidental industrial companies. They are based on the pragmatic and manufacturing related philosophies of six sigma and lean thinking. Lean thinking derived from the Toyota Production System in the 1950s and evolved ever since (Womack, Jones, and Roos 1990). Shah, Chandrasekaran, and Linderman (2008) present lean production to be describable differently such as a philosophy, a batch of principles and as a pack of practices. They go on and elaborate its definition to be based on a philosophy of eliminating waste within a product's value stream and practices to be related with quality management, pull production, preventive maintenance and man resource management. Wong, Ignatius, and Soh (2012) provide with an index to measure leanness of lean transformation of an organisation. Wong, Ignatius, and Soh (2012) understand leanness to be the degree of the adoption and implementation of lean philosophy in an organisation.
The six sigma concept was developed and introduced by Morotola and awarded with the Baldrige National Quality Award in 1988 (Oakland 2008). Besides being a measure for process variation through capability it is also described as a philosophy for improvement with statistical tools and metrics (Gowen III, Stock, and McFadden 2008; Shah, Chandrasekaran, and Linderman 2008). While originating from manufacturing processes, nowadays, six sigma is implemented in activities such as marketing, purchasing, invoicing and answering customer calls among others to increase customer satisfaction through continually improving its processes (Antony, Gijo, and Childe 2012). It is also related to process error reduction within a process improvement initiative and many of the tools and techniques of Table 1 are applied (Gowen III, Stock, and McFadden 2008; Shah, Chandrasekaran, and Linderman 2008).

Besides the richness and completeness of these philosophies and manufacturing management strategies the selection of the project to develop or the next problem to solve is not always a defined and structured process. Kumar, Antony, and Cho (2009) identified room of improvement when selecting the right project within the six sigma initiative. Difficulties are independent of the company's performance or level of good administration. $\mathrm{Hu}$ et al. (2008) assumed that decisions are based on experience and subjective preferences of individual decision-makers and that the significance of quantitative support in project selection increases with the number of available projects. Consequently, the need for a tool that assists in prioritising mutually exclusive alternatives as selection is demonstrated.

Table 2 was built-up to summarise methods and styles of presenting results around selecting improvement projects or selecting lean tools, respectively, in literature. The Analytic Hierarchy Process (AHP) or variations of it are used and results are presented as ranking of alternatives (Ahire and Rana 1995; Singh et al. 2006; Van de Water and Vries 2006, Kumar, Antony, and Cho 2009). Van de Water and Vries (2006) presented in an overview of technical papers of AHP modelling around quality management. The input, however, is mostly qualitative data retrieved from experts. A fuzzy AHP method is proposed by Bilgen and Şen (2011) whose objective is to identify the best alternative given their defined criteria. $\mathrm{Hu}$ et al. (2008) proposed a matrix of alternatives based on a multi-objective mathematical model based on lean and Six Sigma concepts. They demonstrate that their decision support system can be used in the context of lean and six sigma concept implementation. ANP, also developed by Saaty (1980), is rather a network presentation of nonlinear relationships between elements (Büyüközkan and Öztürkcan 2010).

All methods presented in Table 2 have cost, benefit, risk or effort-related criteria. Some authors also consider 
Table 2. Methods and presenting style in selecting quality improvement projects.

\begin{tabular}{|c|c|c|c|c|}
\hline Selection Method & $\begin{array}{l}\text { Presenting } \\
\text { style of results }\end{array}$ & Criteria & Project & Author \\
\hline $\begin{array}{l}\text { Analytical Hierarchy Process } \\
\text { (AHP) }\end{array}$ & $\begin{array}{l}\text { Ranking of } \\
\text { alternatives }\end{array}$ & $\begin{array}{l}\text { Organizational fit; customer } \\
\text { satisfaction, employee satisfaction; } \\
\text { effort and impact variables }\end{array}$ & $\begin{array}{l}\text { Quality } \\
\text { improvement } \\
\text { project, TQM } \\
\text { project } \\
\text { selection }\end{array}$ & $\begin{array}{l}\text { van de Water and Vries } \\
\text { (2006); Kumar, Antony, } \\
\text { and Cho (2009); Ahire } \\
\text { and Rana (1995) }\end{array}$ \\
\hline $\begin{array}{l}\text { Multi-objective mathematical } \\
\text { model }\end{array}$ & $\begin{array}{l}\text { Matrix } \\
\text { presentation of } \\
\text { alternatives }\end{array}$ & Costs and estimated benefits & $\begin{array}{l}\text { Implementing } \\
\text { lean and six } \\
\text { sigma concepts }\end{array}$ & Hu et al. (2008) \\
\hline $\begin{array}{l}\text { Fuzzy Analytical Hierarchy } \\
\text { Process (AHP) }\end{array}$ & $\begin{array}{l}\text { Result referral } \\
\text { of AHP to } \\
\text { select a project } \\
\text { alternative }\end{array}$ & $\begin{array}{l}\text { Cost and time of resources; benefits } \\
\text { in cost savings, productivity and } \\
\text { scrap decrease; effects on quality } \\
\text { capacity and energy }\end{array}$ & $\begin{array}{l}\text { Six Sigma } \\
\text { project } \\
\text { selection and } \\
\text { method } \\
\text { adoption }\end{array}$ & Bilgen and Şen (2011) \\
\hline $\begin{array}{l}\text { Fuzzy-logic based multi-preference, } \\
\text { multi-criteria AHP }\end{array}$ & $\begin{array}{l}\text { Ranking of } \\
\text { alternatives }\end{array}$ & & $\begin{array}{l}\text { Lean tool } \\
\text { selection }\end{array}$ & Singh et al. (2006) \\
\hline $\begin{array}{l}\text { Fuzzy analytical network process } \\
\text { (ANP) to prioritize Six Sigma } \\
\text { projects }\end{array}$ & $\begin{array}{l}\text { Ranking of } \\
\text { alternatives }\end{array}$ & $\begin{array}{l}\text { Strategy, Financial, Customer and } \\
\text { Process Improvement }\end{array}$ & $\begin{array}{l}\text { Six Sigma } \\
\text { project } \\
\text { selection }\end{array}$ & $\begin{array}{l}\text { Boran, Yazgan, and } \\
\text { Goztepe (2011) }\end{array}$ \\
\hline $\begin{array}{l}\text { Combined analytic network process } \\
\text { (ANP) and Decision Making } \\
\text { Trial and Evaluation Laboratory } \\
\text { (DEMATEL) approach }\end{array}$ & $\begin{array}{l}\text { Ranking of } \\
\text { alternatives }\end{array}$ & $\begin{array}{l}\text { Strategies and factors: Risk, cost, } \\
\text { benefit, opportunities }\end{array}$ & $\begin{array}{l}\text { Six Sigma } \\
\text { project } \\
\text { selection }\end{array}$ & $\begin{array}{l}\text { Büyüközkan, and } \\
\text { Öztürkcan (2010) }\end{array}$ \\
\hline
\end{tabular}

the organisational fit, customer and employee satisfaction but none is using quantitative or qualitative production data or quality related (real or production derived) data.

The approach resulted from this research is akin to the concept of the Share/Growth matrix (The Boston Box), which was published in 1973 by Henderson, a founder of The Boston Consulting Group (Morrison and Wensley 1991). In that paper, Henderson (1973) described how all products of a company's portfolio are plotted in a $2 \times 2$ matrix according to single attributes (ratio to market share of the biggest competitor and growth in capital opportunity alternatives). He goes on and includes two divisional lines to divide the matrix in four sections (high growth and large market share; high growth and less market share; low growth and large market share; low growth and less market share). Each section is provided with advice on whether to invest or not.

This concept is taught in academia and the basis of further developments by industry. General Electric's (GE) Multifactor Portfolio Matrix and the nine box matrix by McKinsey are prominent successors beside several others (Morrison and Wensley 1991). It gratifies of a high adoption rate of several companies across industries and is mostly used in corporate planning and strategy, and thus one can conclude that its emergence filled an existing gap. Morrison and Wensley (1991) also report the matrix to be a part of curricular in marketing and strategy courses. Identifying product/ strategic business unit (SBU) market positions and assessments and opportunities is one of the major reasons for being taught. They continue and refer to the Share/Growth matrix to be part of the business language one of the main reasons for its use.

\subsection{Research aims and scope}

The main aims of the developed approach were the identification of the most critical NCs that should be prioritised for future improvement projects and to foster the communication of quality related topics to management. The method is a contribution to the field of TQM and targeted to the audience of researchers and practitioners in quality management.

Applying TQM tools and techniques have proven to be beneficial tasks for quality improvement. Selecting the right levers to improve quality is especially important for industries that are characterised by mass production, $100 \%$ manual product inspection and demanding customers. In this context, a novel approach for identifying and prioritising the most promising NCs among a numerous set based on a selection process of multi-attributes is an actual need. The proposed approach integrates elements of TQM tools such as Pareto diagram and FMEA. A popular concept of the marketing area is adopted to be applied in the realm of quality.

In this paper, we make two significant contributions to the area. First, to support the categorisation of NCs, we develop a structured way of defining a weighted multi-attribute evaluation approach and to categorise them in two groups. 
Secondly, in order to support the identification and selection of future improvement projects, we created a two-dimensional matrix partitioned in four sections, that allows the positioning of different NCs, according different weighting strategies, and consequently allowing the prioritisation analysis in a structured way.

After a notional model is presented in the next section, an application case of a real industrial company integrated in the automotive supply chain is given.

\section{NC tracking and prioritisation matrix}

In this section, a methodology overview is given. The tool's functionality, the required inputs and generated outputs are explained and discussed.

\subsection{Purpose and overview}

It is of particular interest for manufacturing companies whose imperfect production processes result in a variety of NCs of a given product of their high volume production processes. This paper proposes a weighted multi-attribute evaluation approach. A structured way of defining attributes is presented, which integrates elements of quality tools such as Pareto diagram and FMEA. NCs are displayed in a $2 \times 2$ matrix with twoweighted multi-attribute axis. One axis targets risk level attributes (x-axis) and the other causes and impacts (y-axis). Thus, in addition to the risk level elements of FMEA NCs are also evaluated in another dimension related to causes and impacts in order to achieve a refined prioritisation. This enables the user to identify and select the improvement projects in structured manner and additionally to follow-up the evolution of the improvement projects through a clear representation of the assessment results. The approach can be applied by decision-makers of industrial companies with several competing improvement projects. Moreover, the approach can be used for any portfolio decision-making problem.

Figure 1 shows the conceptual model of the matrix partitioned in four areas. The top right area (dark shaded) is the 'critical' area that contains NCs that are strongly weighted by both multi-attributes. NCs in this area are critical and impose themselves for immediate actions of improvement. The two areas lightly shaded, one positioned on the top left and the other on the lower right side, are in the 'to be observed' zone. The development of those NCs should be observed over time and selected for improvement if threatened to turn into a 'critical' NC. Individual NCs in these areas can also be selected for improvement projects, if resources are available (or if there are no NCs in the critical area). The lower left quarter is the 'controlled' area with NCs ranked low regarding both multi-attributes (not shaded).

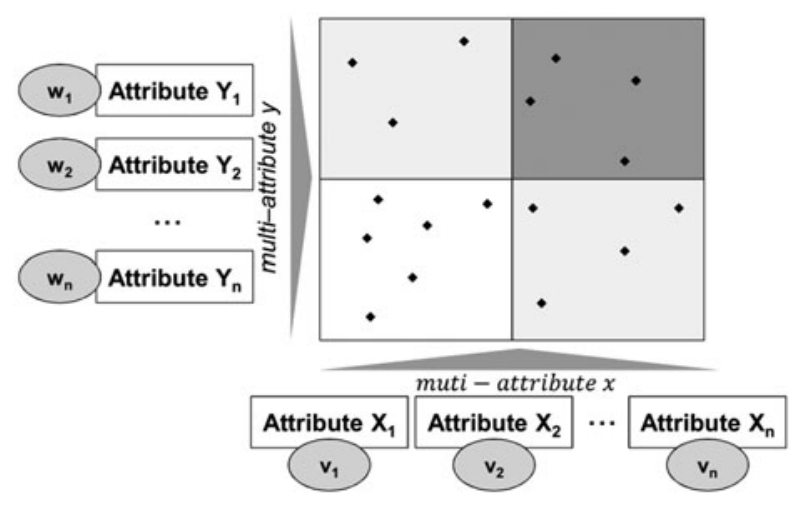

Figure 1. Conceptual model of the matrix with multi-attributes plotted in a $2 \times 2$ matrix.

Following the process steps in Figure 2 guides to create the quality tool. Firstly, the attributes that are relevant for the identification of NCs are defined as a basis for selecting quality improvement projects. Table 3 provides a list, without claiming to be complete, of typical attributes of quality relevant data. Some of them are selected to device the axis of the application case in Section 4.

The attributes that are chosen for creating the NC tracking and prioritisation matrix should be mutually exclusive but do not have to be collectively exhaustive. After defining the attributes one must categorise them into two groups. Each group represents the composition of attributes (multi-attribute) of one matrix's axis. The aggregation of single attributes to compose a multi-attribute can be done randomly or based on common ground, as advance information FMEA is the basis of selecting attributes in Section 4. Expert interviews to identify the rule of aggregating attributes can also be of help. Having defined the attributes and grouped them as a multi-attribute the next step is to gather and treat the data of each attribute. Data can be retrieved from information systems and treated. Hereby, quality tools for example or departmental reports can be used. Borrowing from social science the four basic methods for gathering data can be of assistance. The next step is the scaling of data. The scaling or normalisation is required to fit the single attributes in a multi-attribute model aiming a multi-comparison framework. In order to overcome different spectrum of the attribute's data, the $x_{j}\left(y_{j}\right)$ must be scaled as follows, with $x_{\max }$ being the highest value of the attribute data and $x_{\min }$ being the lowest:

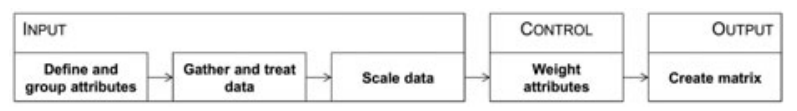

Figure 2. Process steps to develop the tool. 
Table 3. List of attributes for creating the nonconformity prioritisation and tracking matrix.

\begin{tabular}{ll}
\hline Attributes & Comments \\
\hline $\begin{array}{l}\text { Risk level attributes } \\
\text { Occurrences of NCs }\end{array}$ & $\begin{array}{l}\text { Total numbers of NCs in a given } \\
\text { period }\end{array}$ \\
Severity & $\begin{array}{l}\text { Hypothetical impact on safety of } \\
\text { a given NC if delivered to and } \\
\text { used by the customer }\end{array}$ \\
The difficulty of detecting a \\
specific NC
\end{tabular}

$$
\begin{gathered}
x_{i}=\frac{x_{j}-x_{\min }}{x_{\max }-x_{\min }} \\
y_{i}=\frac{y_{j}-y_{\min }}{y_{\max }-y_{\min }}
\end{gathered}
$$

After data gathering and set-up for further numerical manipulation the proposed tool requires the definition of weights. This allows controlling the importance of the attributes aiming to identify the most critical NCs for different levels or types of quality targets scenarios. The final output consists of a matrix where the several NCs are plotted in different severity zones depending on the strengths given to each weight. These last two steps are described in detail in the following section.

\subsection{Formalisation and use}

In this section, the step of weighting the attributes is formalised and the multi-attribute matrix construction is described.

A lot of possible methods to determine the weights of the attributes can be considered. A rather simple one is to leave this as an input for the user to establish levels of importance, based on his or her preferences given towards the individual attributes. A different approach is to use the weights based on feedback given. Feedback could be the cost of the attribute which are determined prior to modelling the matrix. Based on historical data and cost of the attributes one can calculate the weights. Also, company philosophy can be taken into account if certain attributes comply better with mission statements of the company. Identifying weights based on pairwise comparison as done for instance in the Analytic Hierarchy Process (Saaty 1980), which is used plentifully as one can see in Table 2, is also thinkable.

The objective is to create a scatter chart with elements positioned based on their $\mathrm{x}$ and $\mathrm{y}$ values, which are composed by other attributes as schematically shown in Figure 1.

One can state:

$$
\begin{aligned}
& x_{k}=\sum_{i=1}^{n} x_{i} * v_{i} \\
& y_{k}=\sum_{i=1}^{n} y_{i} * w_{i}
\end{aligned}
$$

With $v_{i}, w_{i} \in[0,1]$ and $\sum_{i}^{n} v_{i}=1$ and $\sum_{i}^{n} w_{i}=1$

As a result one calculates positions of elements within the scatter diagram based on weighted attributes: $P_{k}\left(x_{k} ; y_{k}\right)$

The farther away from the point of origin of one axis, the more extreme the element is based on its attributes and weights given (please refer to Figure 1).

\subsection{Strength and limitations}

The main strength of the approach is the ability of objective decision-making, which is based on weighted multi-attributes. In addition to that changing the settings of the weights might result in different matrix graphs and can uncover NCs that should be prioritised, which might have been neglected otherwise. Furthermore, the approach allows monitoring the NCs, which have been selected in previous periods for improvement. If the improvement actions take effect the NCs should recede from the critical area of prioritisation.

One has also to mention that the approach is highly illustrative in terms of result representation. The matrix is partitioned in four sections, which makes it intuitive to identify the critical or controlled NCs according to the weighted relevant attributes. The presentation style is analogue to an already established approach in marketing and one can take advantage of the publicity for communicating quality-related topics in business language. Lowy and Hood (2004) name the simplicity of a $2 \times 2$ matrix as one of its greatest characteristics and state that $2 \times 2$ thinking improves clarity, honesty and quality of problem-solving. Thus, it is in accordance with nowadays trends of visual management. 
In addition to that the approach is highly flexible considering the attributes. All inputs are not only interchangeable but also exchangeable with new attributes that are of interest to be taken into consideration for the evaluation.

The proposed approach fills the gap of prioritising NCs for future improvement projects based on multi-criteria.

A drawback of this approach is that its use is supposed to be an offline tool and thus requires periodical updates. If wanted to act in real time it is upgradable with additional IT development to operate as an online tool according to the on-site IT environment. However, with restriction to flexibility since attributes are then not as easily exchangeable. Moreover, qualitative input data requires reassessments over time on whether the assessments still hold. This means that participating people for qualitative input must be re-interviewed. Besides the previous mentioned objective decision-making is at stake when over-weighting one specific attribute and neglecting the others. When doing this the multi-attribute decision-making is turned back to a single attribute decision making.

\section{Application case}

The case study under analysis was developed on a mature producer of a high technology product integrated in the supply-chain of the automotive industry. A quality management system certified according to various standards such as DIN EN ISO 9000, DIN EN ISO 9004 and ISO/TS 16,949 relates to all business and operating processes.

The product of the case study is a complex product involving several areas of engineering knowledge and it requires a sequence of several manufacturing processes to be produced. A final product inspection appraises outcomes of the production steps upon conformance to requirements prior to shipping. The product inspection is entirely human based and performed on $100 \%$ of the production volume. The previous production steps are mixing of raw materials, assembling of subassemblies and an injection akin process, among others. Hereby, the spectrum of processes reach from fully automated, fully manual to semi-automated. The company produces a high technology and complex product which is varying in size and composition. The product is produced in a large production volume and production-related data are massively available. The products' processes are very complex. Thus, causes for NCs are multiple and attributable to process failures, machine stoppages, incorrect composition, quality of raw material or human error. Specific for the product is that the vast majority of NCs are only detectable at the finished product. Furthermore,

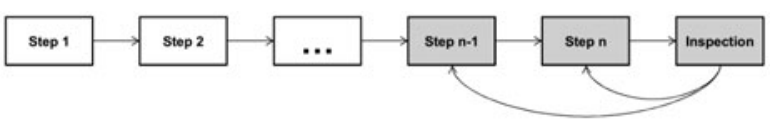

Figure 3. Production process steps of the case under analysis.

NCs vary from minor cosmetic to severe imperfections, which are not recoverable.

For this study, the last two production steps are analysed and the data retrospectively retrieved at the inspection process at the end of the manufacturing line. This can be seen schematically in Figure 3. Each machine at each production step leaves distinct evidence at the product that is identified and gathered at the IT system. A result of the inspection is an evaluation decision of the product to be conforming or nonconforming to requirements. Conforming products are approved and forwarded to be shipped to the customer. Nonconforming products are registered and characterised by the type of $\mathrm{NC}$ and evaluated upon recoverability. In addition, information about the history of production steps is available, containing information regarding the specific machines the product had passed. Both steps, step n-1 and $n$ in Figure 3 consist of several machines and each product has to pass exactly one machine in each step. Hence, a clear identification which machine of the two production steps is the contributor of the NC is not possible retrospectively at the appraisal of the finished product.

The categories of the NCs are visual, functional and geometrical; additional information is given regarding the location at the product. After having the list of NCs, one can generate the NC Tracking and Prioritisation Matrix, following the previously mentioned formalisation instructions.

\subsection{Defining the attributes}

Defining the attributes is the first step of building the matrix. The authors suggest composing the $\mathrm{x}$-axis with attributes related to the risk level and the $y$-axis with attributes related to causes and impacts.

Attributes on the $\mathrm{x}$-axis comprise the attributes of the known systematic method FMEA: frequency of occurrences, severity and detection probability. Attributes on the y-axis are composed by scrap rate, concentration of NCs to single machines and customer complains related to the NCs. This approach considers in addition to the important risk level attributes also the company specific attributes related to the installed quality system.

The proposed attributes in Table 4 are all data related to quality and represent production related data regarding the NCs. The selected data stem from both quantitative and qualitative data. The selection of the remaining attributes besides the ones of the FMEA method is based 
Table 4. List of attributes of the application case.

\begin{tabular}{|c|c|c|c|}
\hline Attribute & Attribute Name & Type of data & Comment \\
\hline $\mathrm{X}_{1}$ & Frequency of NC occurrences & $\begin{array}{l}\text { Quantitative } \\
\text { data }\end{array}$ & $\begin{array}{l}X_{1}=\sum^{x_{1, i}} \\
\text { The number of frequency of occurrences of a specific NC. }\end{array}$ \\
\hline $\mathrm{X}_{2}$ & Severity of NC & $\begin{array}{l}\text { Qualitative } \\
\text { data }\end{array}$ & $\begin{array}{l}\text { Hypothetical impact on customer's safety if NC remains undetected, } \\
\text { delivered to customer and used. }\end{array}$ \\
\hline $\mathrm{X}_{3}$ & Detection & $\begin{array}{l}\text { Qualitative } \\
\text { data }\end{array}$ & $\begin{array}{l}\text { Likelihood of a specific NC to not be detected by the inspection } \\
\text { system. }\end{array}$ \\
\hline $\mathrm{Y}_{1}$ & $\begin{array}{l}\text { Concentration of NCs to machines } \\
\text { (Herfindahl-Index) }\end{array}$ & $\begin{array}{l}\text { Quantitative } \\
\text { data }\end{array}$ & $\begin{array}{l}Y_{1, i}=\max \left(H H I_{1,1} ; H H I_{1,2}\right) \text { with } H H I_{1, i}=\sum_{i=1}^{N} a_{i}^{2} \text { and } a_{i}=\frac{x_{j}}{\sum_{j}^{N} x_{j}} \\
\text { HHI } \\
\text { represents the concentration of an individual NC to single machines. }\end{array}$ \\
\hline $\mathrm{Y}_{2}$ & Customer evaluation & $\begin{array}{l}\text { Quantitative } \\
\text { data }\end{array}$ & $\begin{array}{l}\text { Data analysis regarding customer complaints and warranty claims, } \\
\text { which are related to specific NCs. }\end{array}$ \\
\hline $\mathrm{Y}_{3}$ & Scrap rate & $\begin{array}{l}\text { Quantitative } \\
\text { data }\end{array}$ & $Y_{3 i}=\frac{y_{j}}{\sum_{j}^{N} y_{j}}$ \\
\hline
\end{tabular}

on expert interviews and validation cycles and were all evaluated to be important.

Frequency of occurrences is the number of occurrences of one specific type of $\mathrm{NC}$ among the total number of all occurring NCs. It is an important indicator to quantify the magnitude of the occurrences of NCs. If the quality tool Pareto diagram already exists, its data can be reused as a model input and the corresponding data can be directly scaled as previously described. Figure 4 presents the Pareto diagram of the NCs in the application case. All 35 different NCs are presented with their corresponding number of occurrences.

The severity attribute is addressing the hypothetical impact on customer's safety if a by the inspection system undetected product with an NC failed in use by the customer. The harm is estimated on a Likert scale based on interviews with experts from production, quality and engineering departments. Although, the information is based on rough estimates of expert interviewees and biased by subjectivity it provides very important information about consequences if NCs unintentionally pass the inspection system.

The detection attribute is related to the effectiveness of the inspection. Data were gathered through expert

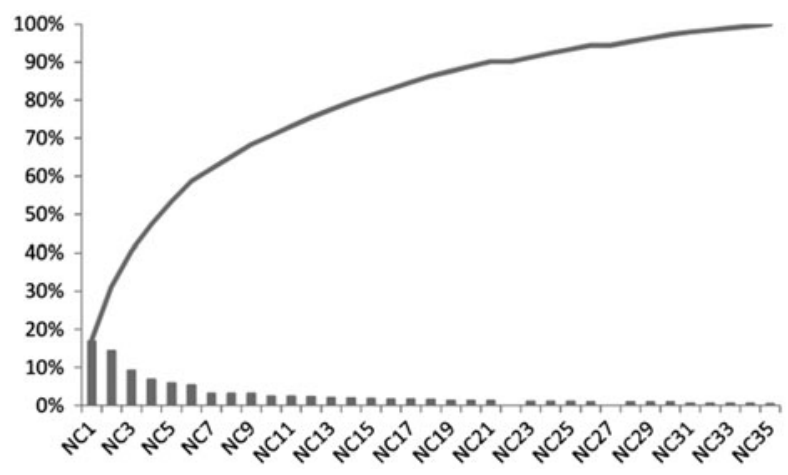

Figure 4. Pareto diagram of NCs of the application case. interviews from the company's quality department. The experts were asked to rate the likelihood of each specific $\mathrm{NC}$ to not be detected by the inspection system on a scale of 0 to 10 . The value 0 represents that the $\mathrm{NC}$ is always detectable and the value 10 indicates that the $\mathrm{NC}$ is impossible to be detected. This is an important attribute as selection and prioritisation criterion with the goal to diminish the NCs with a high likelihood to be undetected by the inspection system.

As previously mentioned, the appraisal of the product is done at the end of the manufacturing line. In that way (unless very obvious to the experienced inspector, which is valid for the minority of the cases), a direct root cause for the NC is not possible to identify. Nevertheless, the authors suggest to process existing data to highlight possible contributors to the creation of NCs. The database contains information of the production steps that the product undertook, which makes each product retraceable to the production steps and the path of machines that the product took becomes visible. After collecting data at the end of the production line and treating it, one can relate NCs to production machines. The production machines that show higher occurrences of specific NCs can be identified. For this analysis it is assumed, for sake of simplification, that if the $\mathrm{NC}$ is related with a machine the NC was caused by that machine. The authors suggest analysing this information with a method from economics to identify the concentration of the NC production: The Herfindahl Index (Hirschman 1964). Since each conforming and nonconforming product passes exactly one machine at each production step, all NCs add up to the total sum of NCs. However, they do not distribute equally to them and one machine might show a higher relation to a specific $\mathrm{NC}$ than another. Identifying the degree of concentration of the NCs to single machines can be of valuable information and follows the economic concept of the Herfindahl-Hirschman Index (HHI), also known as the Herfindahl Index (Rhoades 1993). 
The HHI is a method to statistically measure concentration and express it through an index value. Rhoades (1993) report its application in different contexts such as the measurement of concentration of income in households or to measure concentration of output of companies of specific industrial markets. This author states the HHI as the sum of the squared market shares (MS) of the number of the sample size e.g. households or companies.

with

$$
\mathrm{HHI}=\sum_{i=1}^{N}(\mathrm{MS})^{2}=\sum_{i=1}^{N} a_{i}^{2} \text { and } a_{i}=\frac{x_{i}}{\sum_{j}^{N} x_{j}}
$$

In the figurative sense, the production machines of one production step are producing output - NCs - and the concentration of it is measured. This concentration or HHI is measured for production step $n-1$ and $n$ for each NC, respectively. The maximum index value of the two production steps for a specific $\mathrm{NC}$ is considered with the assumption that the higher the HHI value the more NCs do concentrate to single machines. Thus, the likelihood of single contributors of $\mathrm{NC}$ production is increased. This assumption must be proven to be correct if further analysis of root causes takes place. Figure 5 depicts the maximum HHI value of two consecutive production steps of the application case. Additional data processing and visualisation yield information to which exact machine specific NCs are concentrated on. Considering this attribute provides indication for a possible source of root causes at machines, which are well worth to further investigate. It is also in accordance on the company's standard of continuous improvement.

The customer evaluation attribute is related to customer complaints and warranty data that are collected by the company. This data must be related and if necessary adapted to the NC coding of the inspection. A Pareto analysis of the customer complaints can serve for analysis. This attribute is important and in accordance with the company's quality system. The company claims customer complaints and warranty rates to be low due to possible penalties for delivering nonconforming products and reputation loss.

The scrap rate attribute is the ratio of positive decisions to scrap the product to its total number of $\mathrm{NC}$ occurrences of a given period. The total number of NCs includes all incidents such as scrap, rework or false negative product evaluation. Figure 6 depicts scrap rate of the

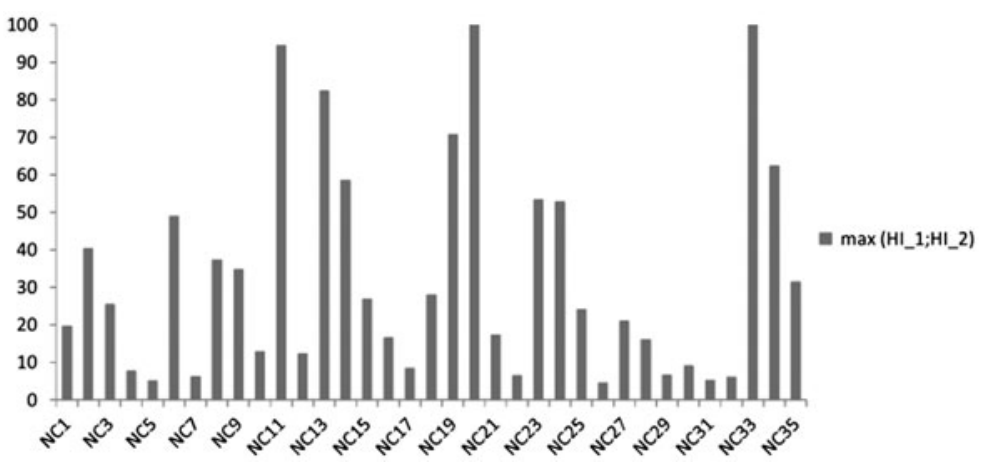

Figure 5. Maximum value of the HHI of two consecutive production steps of the application case.

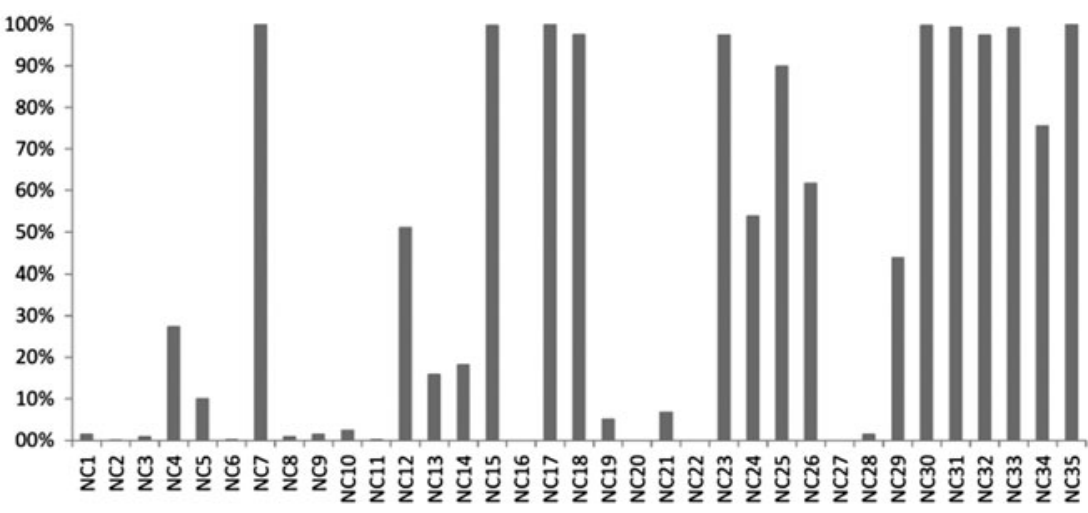

Figure 6. Scrap rate of NCs of the application case. 
NCs of the application case of a given period. Some NCs show a $100 \%$ scrap rate, which means that the product is scraped every time an NC is detected by the inspection system. This is inefficient and expensive to the company due to production losses. Furthermore, focusing on reducing scrap is an important attribute to consider and used to be considered as one of the main criterion for selecting improvement projects by the company.

\subsection{Gathering and treating data}

After defining the attributes, the production resident data are computed to calculate the scores of the relevant attributes as presented in Table 4. At each production step, the product has a specific identifier in form of a barcode. At every production step, information is input to the database with machine number, operator number, time and date. At the end of the production process, the product is evaluated by the inspection process upon conformance. If stated as nonconforming, the type of $\mathrm{NC}$ and the decision of whether to scrap or recover the product is recorded. After retrieving the relevant data from the database it is treated according to the formula given in Section 4.1. The result of the data treatment can be seen in Appendix 1.

\subsection{Scaling data}

If data are gathered and treated, one has to scale it for it to fit into a composed multi-attribute axis. Within the data sample of an attribute, the maximum and minimum values are identified and every data-set element is scaled based on the presented equations in Section 3.1 (Equations 1 and 2).

Table 5 provides an example of scaling based on those scaling equations. In the presented application case, the gathered data of the attribute frequency of $\mathrm{NC}$ occurrences has a maximum of 7026 and minimum of 0 (see Appendix 1). Thus, the scaling equation can be assembled as follows:

$$
x_{i}=\frac{x_{j}}{7026}
$$

Appendix 1 provides a full overview of all attributes together with the corresponding scaling information.

\subsection{Weighting attributes}

The number of combinations of allocating weights to attributes is infinite and so are the outcomes of these particular matrices.

In this study, the authors propose a two-step approach, each containing three sub-steps, to generate result matrices. In the first step, equal weights are given to the attributes at 'risk level' $\mathrm{x}$-axis. In the second step, the attribute severity is given full weight because the authors evaluate it as the most important attribute at the 'risk level' $\mathrm{x}$-axis. The following three sub-steps contain setting full weight to each of the 'causes and impacts' y-axis. Thus, in each step three matrices are generated, which yields six matrices in total.

Table 5. Extraction of scaling data.

\begin{tabular}{lllllllr}
\hline & Occurrences & Severity & Detection & HHI & HHI2 & Customer complaints & Scrap rate \\
\hline Max & 7026 & 4.67 & 10 & 0.13 & 0.68 & 1 & 1 \\
Min & 0 & 0 & 0 & 0.0038 & 0 & 0 & 0 \\
\hline
\end{tabular}

Table 6. Strategies to set weights to generate results with the tracking and prioritisation tool.

\begin{tabular}{|c|c|c|c|}
\hline Strategy & $v_{i}$ & $w_{i}$ & Comments \\
\hline 1. & & & Average weighting of 'risk level' $\mathrm{x}$-axis \\
\hline (a) & $v_{i}=\frac{1}{n}=\frac{1}{3}($ for $n=3)$ & $w_{1}=1 ; w_{2}=w_{3}=0$ & $\begin{array}{l}\text { Identify NCs with average weighting of risk level } x \text {-axis and a high } \\
\text { concentration of NCs to machines }\end{array}$ \\
\hline (b) & $v_{i}=\frac{1}{n}=\frac{1}{3}($ for $n=3)$ & $w_{1}=0 ; w_{2}=1 ; w_{3}=0$ & $\begin{array}{l}\text { Identify NCs with average weighting of risk level } x \text {-axis and a high } \\
\text { numbers of customer complaints }\end{array}$ \\
\hline (c) & $v_{i}=\frac{1}{n}=\frac{1}{3}($ for $n=3)$ & $w_{1}=w_{2}=0 ; w_{3}=1$ & $\begin{array}{l}\text { Identify NCs with average weighting of risk level } \mathrm{x} \text {-axis and a high scrap } \\
\text { rate }\end{array}$ \\
\hline 2. (a) & $v_{1}=0 ; v_{2}=1 ; v_{3}=0$ & $w_{1}=1 ; w_{2}=w_{3}=0$ & $\begin{array}{l}\text { Maximum weighting of one attribute Severity } \\
\text { Identify NCs that are severe and highly concentrated to machines }\end{array}$ \\
\hline (b) & $v_{1}=0 ; v_{2}=1 ; v_{3}=0$ & $w_{1}=0 ; w_{2}=1 ; w_{3}=0$ & $\begin{array}{l}\text { Identify NCs that are severe and have a high number of customer } \\
\text { complaints }\end{array}$ \\
\hline (c) & $v_{1}=0 ; v_{2}=1 ; v_{3}=0$ & $w_{1}=w_{2}=0 ; w_{3}=1$ & Identify NCs that are severe and have a high scrap rate \\
\hline
\end{tabular}


The proposed strategies to generate results are summarised in Table 6. Each strategy presented has a specific setting of weights according to what is sought as mentioned in the comments. The weights $v_{i}$ refer to the attributes $x_{i}$ and $w_{i}$ to the $y_{i}$ attributes in Equations (3) and (4).

The strategies presented above are proposed by the authors but should not confine the user of the approach to extract data differently. For instance, one could perform the same analysis for each of the remaining two attributes of the $y$-axis as done in strategy $2 a, 2 b$ and $2 c$ in Table 6.

\subsection{Matrix output - results and discussion}

In this section, the results of the presented approach in the context of the case study are presented. Herby, the $\mathrm{NCs}$ are plotted in a $2 \times 2$ matrix on composed axis ordinates with different weights and portrayed in Figures 7-12.

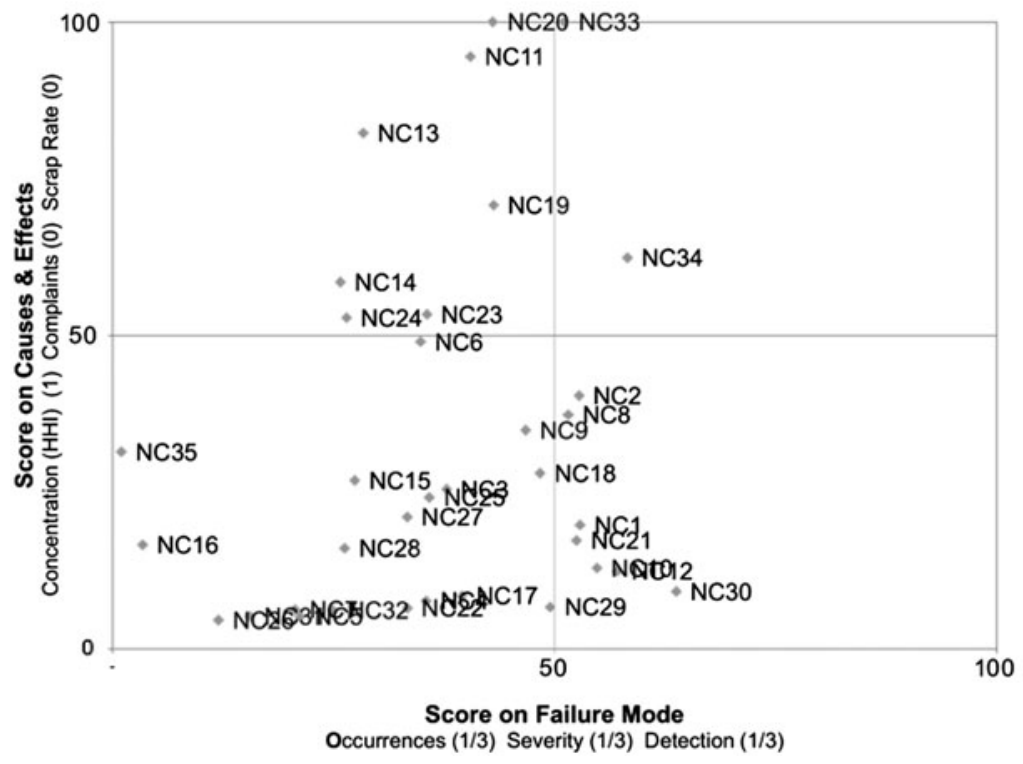

Figure 7. Matrix result: all attributes of $\mathrm{x}$-axis with average weights and full weight to concentration of NCs at y-axis.

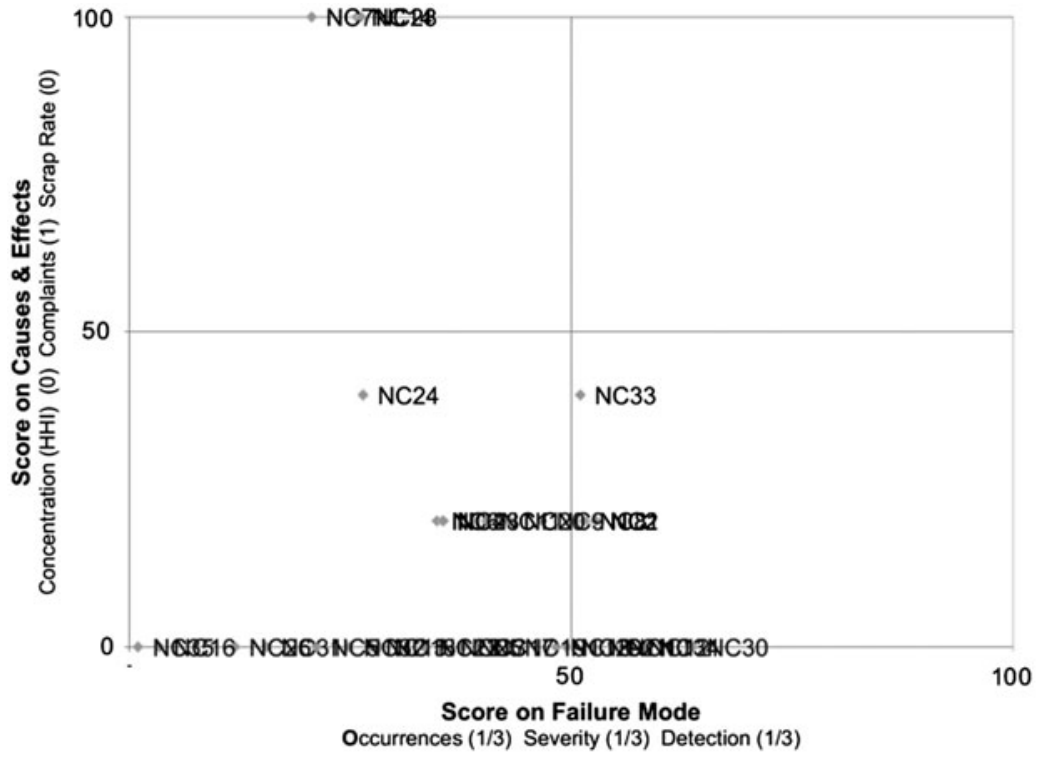

Figure 8. Matrix result: all axes with average weights at $\mathrm{x}$-axis and full weight to Complaints at $y$-axis. 


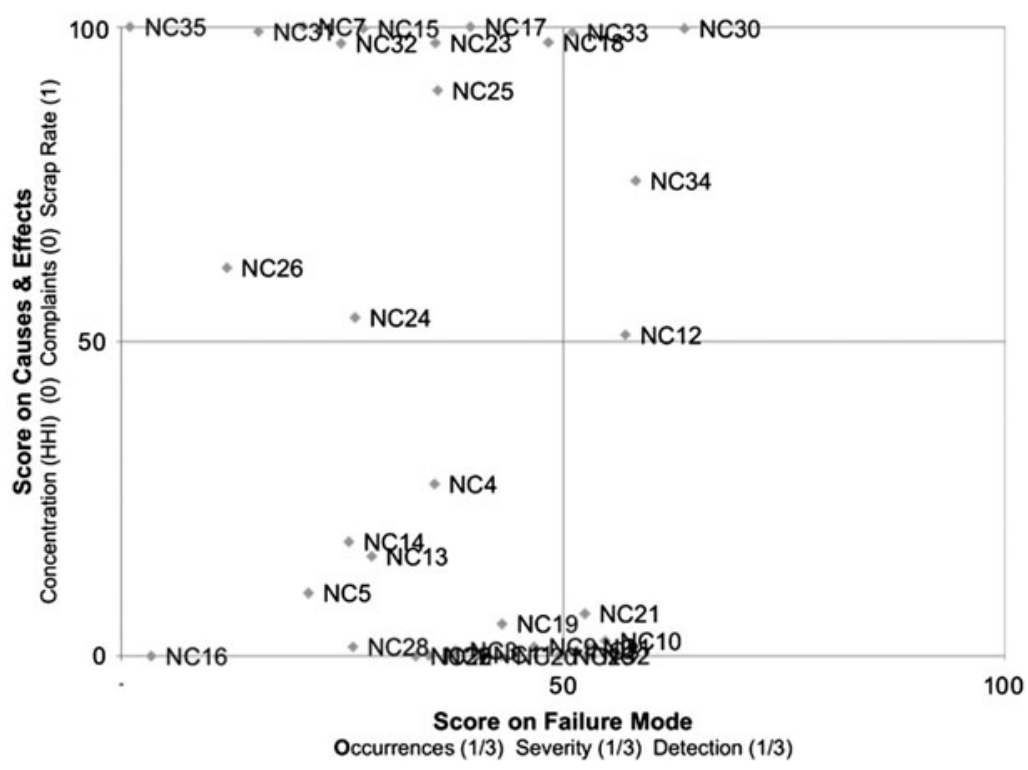

Figure 9. All axes with average weights at x-axis and full weight to scrap rate at y-axis.

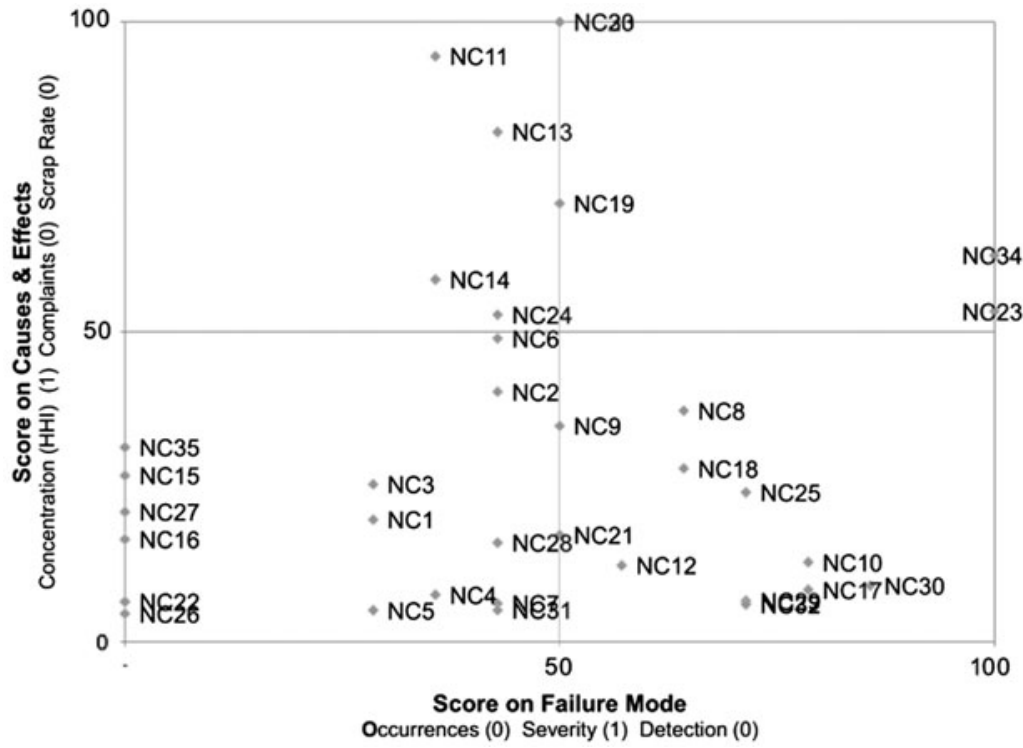

Figure 10. Matrix result: maximum weights of $\mathrm{x}$-axis attribute severity and $\mathrm{y}$-axis concentration.

\subsubsection{Average weighting of risk level axis}

To begin obtaining results the first strategy of Table 6 is followed and the weights of the risk level axis are equally weighted. With equal weights at the 'risk level' axis graphs are generated with full weights of each attribute at the 'causes and impacts' axis. This manner of setting weights can be considered as a refined FMEA selection. All NCs passing the score of 50 on the 'risk level' axis are already selected by FMEA but need to additionally achieve high scores on the 'causes and impacts' axis. The results are presented in Figures 7-9.
Figure 7 shows a matrix result with average weights of attributes at the 'risk level' axis and full weight of the concentration attribute of 'causes and effect' axis. By calibrating the weights in that manner one seeks to identify the NCs that are given priority according to the risk level analysis and to the ones which occur concentrated to individual machines. Consequently, they do qualify for an efficient investigation of root cause analysis at the corresponding machines. The outcome of this calibration of weights results in identifying two NCs (NC33 and NC34) in the critical area - the top right quarter. The 


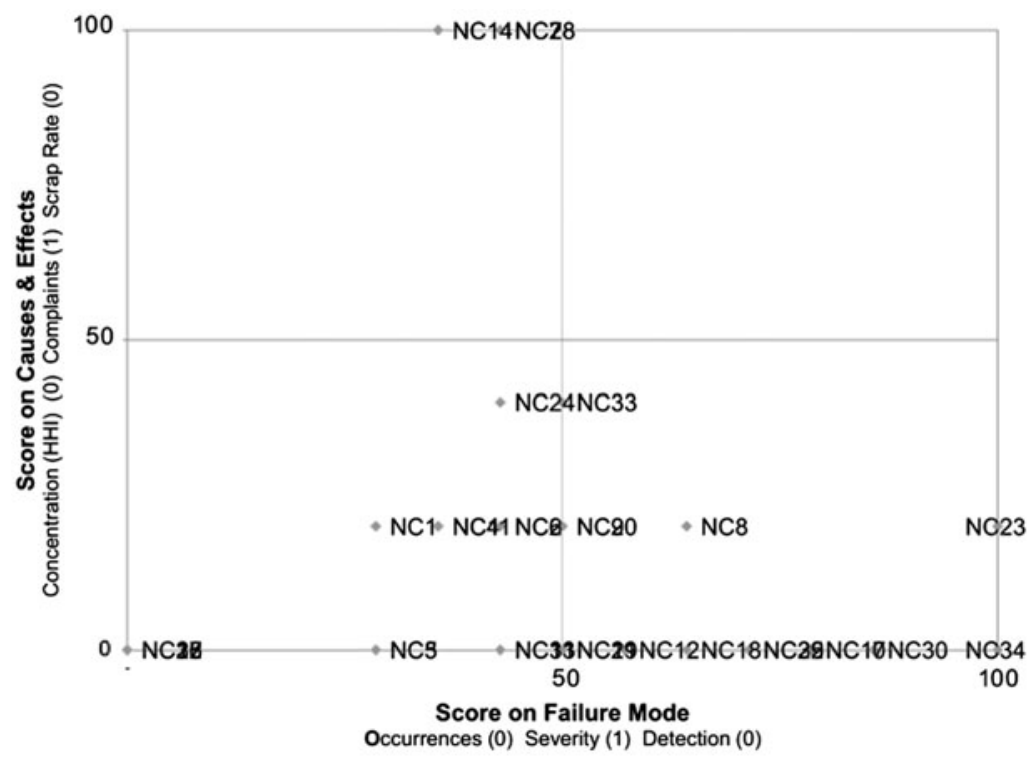

Figure 11. Matrix result: maximum weights of $\mathrm{x}$-axis attribute severity and $\mathrm{y}$-axis complaints.

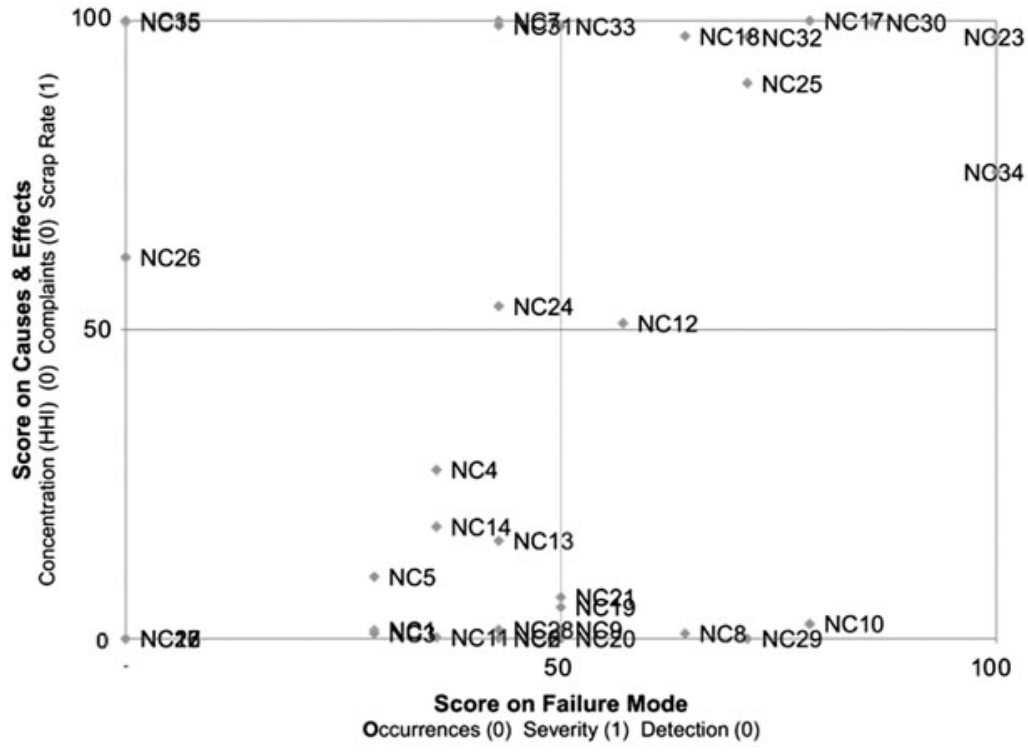

Figure 12. Matrix result: maximum weights of $x$-axis attribute severity and $y$-axis scrap rate.

two 'to-be observed' quarters are filled with some NCs but the majority appears in the lower left quarter. Hence, priority of further investigation of improving quality should be given to NC33 and NC34. Complementary analysis has to be done to identify root causes and to introduce measurement for improvement.

Figure 8 presents a matrix result with average weights of attributes at the 'risk level' axis and full weight of the complaints attribute of 'causes and effect' axis. By calibrating the weights in that manner one seeks to identify the NCs that are given priority according to the risk level analysis and which are complaint about most by customers. Identified NCs would consequently qualify for further root cause analysis and improvement to reduce the number of customer complaints. The outcome of this calibration of weights, results in no identification of NCs in the critical area - the top right quarter. The two 'to-be observed' quarters are filled with some $\mathrm{NCs}$ but the great majority appears in the lower left quarter. Hence, no immediate priority of further investigation of improving quality can be identified in this calibration of weights. 
Figure 9 presents a matrix result with average weights of attributes at the 'risk level' axis and full weight of the scrap rate attribute of 'causes and effect' axis. By calibrating the weights in that manner one seeks to identify the NCs that are given priority according to the risk level analysis and which have a high scrap rate. Eliminating the root causes of those NCs in following improvement projects would reduce the number of scrap, which entails an increase of profit through additional generated sales and reduced failure costs. The outcome of this calibration of weights results in identifying four $\mathrm{NCs}$ in the critical area - priority of further investigation should be given to NC 12, NC30, NC 33 and NC34. The two 'to-be observed' quarters are filled with some NCs but the majority appears in the lower left quarter.

\subsubsection{Maximum weighting of two attributes}

After retrieving results as described in the previous section, the second step allocates maximum weights to one attribute of each ordinate axis. The attribute at the risk level' axis - severity - is held steady while results are generated by altering the maximum weight setting among each one of the three attributes at the 'causes and impacts' axis.

Results of the matrices are portrayed in Figures 10-12.

The calibration of maximum weight setting to severity and concentration is depicted in Figure 10. The severe NCs that occur highly concentrated to individual production machines are identified. By focusing on the prioritised ones and identifying eliminating root causes one can reduce the number of occurrences of severe NCs, which reduces the risk of delivering undetected severe NCs to customers. The outcome of this weight calibration, results in identifying five NCs in the critical area - the top right quarter to which priority of further investigation should be given (NC 19, NC20, NC 23, NC33 and NC34).

The calibration of maximum weight setting to severity and complaints is portrayed in Figure 11. The severe NCs, about which customers complain a lot, are identified. Focusing on the prioritised ones and identifying eliminating root causes one can reduce the number of severe NCs, with high customer complaints. The outcome of this weight calibration, results in the identification of no $\mathrm{NC}$ in the critical area - the top right quarter. Hence, no immediate priority to specific NCs of further investigation in improving quality identified in this calibration of weights needs to be given.

The outcome of the calibration of maximum weight setting to severity and scrap rate is presented in Figure 12. The severe NCs that are scrapped on a high number are identified. Focusing on the prioritised ones and eliminating root causes can contribute to the reduction of the number of severe NCs, which are highly

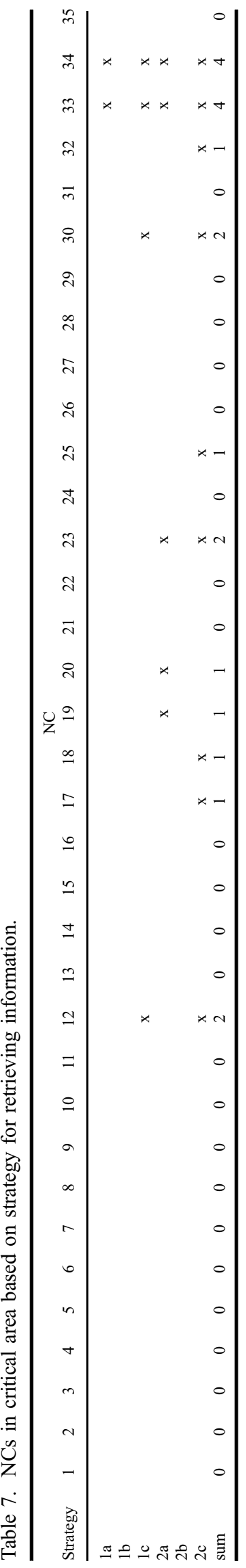



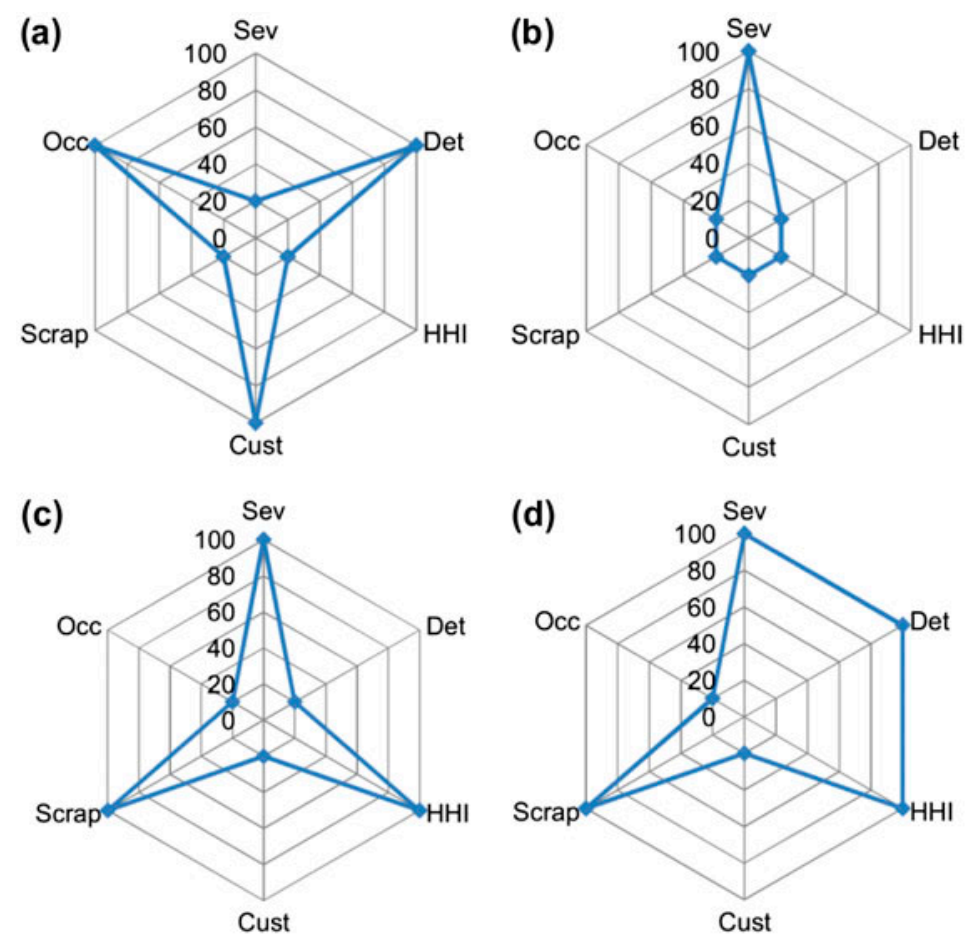

Figure 13. Typification of NCs profiles. (a) High occurrence, high customer complaints and poor detection efficiency; (b) high severity and low score on all remaining attribute and great detection rate (c) high severity, highly concentrated, high scrap rate and great detection rate with low score on all other attributes and (d) high severity, poor detection, highly concentrated and high scrap rate.

scrapped. The identified NCs, to which priority of further investigation of improving quality should be given, are $\mathrm{NC} 12, \mathrm{NC} 17, \mathrm{NC} 18, \mathrm{NC} 23, \mathrm{NC} 25, \mathrm{NC} 30, \mathrm{NC} 32$, NC33 and NC34.

In addition to the identified NCs located in the critical area of Figures 7-12 other NCs may qualify for further selection as well. If resources are available, NCs in the to-be observed areas (lower right and upper left corner) can be selected additionally for further investigation and improvement.

Table 7 summarises the NCs found in the critical areas of the graphs from Figure 7-12. For each strategy with its corresponding setting of weights of attributes, the NC type found in the critical area is listed.

In a structured manner, critical NCs can be identified upon weighted multi-attributes and prioritised for being selected for future improvement projects. The different strategies for setting weights may lead to different prioritisation results. If the user is determined about setting the weight the result is explicit. If not, different weighting strategies should be applied and results analysed to foster the informed decision-making. For example, one possible strategy can be to select the NCs that are prevalently prioritised by the different strategies of setting weights. In this application case these are, according to Table 7, NC 33 and NC 34.

\subsection{Complementing presentation of NC profile figures}

In addition to the result presentation in the form of matrices, the authors suggest to perform a particular analysis for some selected NCs. This is done by firstly, defining generic profiles of NCs in shapes and interpreting what the shape denotes. Secondly, the real NC shape profiles are compared with the generic shape profiles. With the proposed visualisation it is possible to immediately understand the overall performance of an $\mathrm{NC}$ according the different attributes.

Some generic profiles of NCs are depicted in Figure 13. Each figure presents the six attributes from the application case in Section 4.1 in the shape of a

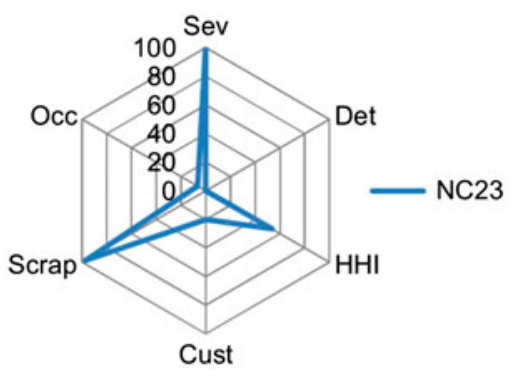

Figure 14. Shape profile of NC 23. 

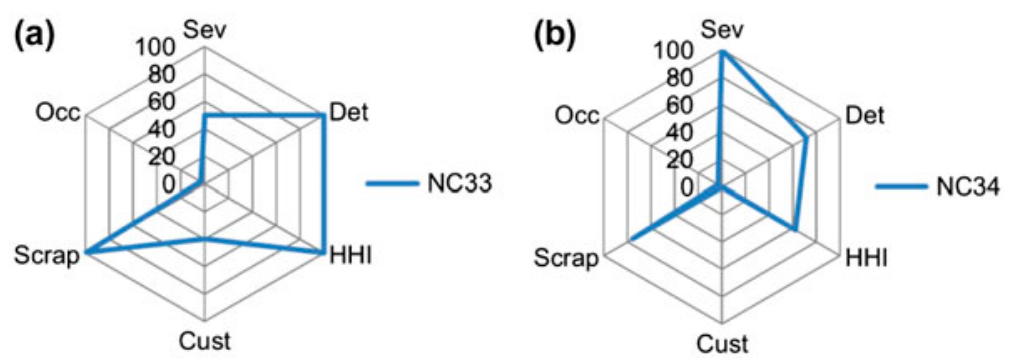

Figure 15. (a) Shape profile of NC 33; (b) shape profile of NC 34.

hexagon. Each attribute is allocated at one corner of the hexagon and the range of the rating is scaled between zero and one hundred with zero being the lowest and originating from the centre. The authors assume that NCs with different values in each attribute will result in different shapes. From those shapes it is possible to accumulate information about the profile of the NCs.

The shape in Figure 13(a) with maximum values at the attributes occurrence, detection and customer complaints is similar to a three-spike-star shape. An NC of this shape occurs frequently, is very hard to detect and customers do complain about it. The NC that occurs are not very concentrated which makes it difficult to identify the root cause at single machines. Fortunately, the NC is not sever and a possible threat for customers. The scrap rate is low, which makes the $\mathrm{NC}$ recoverable without high scrapping expenses.

The shape in Figure 13(b) has a maximum value of the attribute severity. An NC of that shape is very severe but easily detectable. In addition to that it rarely occurs and is not very concentrated to individual machines. Thus, there are only few complaints due to low occurrence and a sound detection.

An NC profile of the shape in Figure 13(c) is very severe, hardly detectable and occurs rarely. Scrap rate is high and the NC occurs very concentrated at individual machines with few customer complaints. There is a high incentive to improve quality of an $\mathrm{NC}$ with such a profile because improvement reduces scrap, which is directly correlated to an improvement in profit. Furthermore, the NC occurs very concentrated to individual machines and the root cause may be quickly identified.

An NC with the shape of Figure 13(d) is very severe and barely detectable. It rarely occurs and is very concentrated to individual machines. Every time it is detected it is scrapped. Fortunately, complaints are low but the potential image loss of an undetected $\mathrm{NC}$ at the customer is beyond price. The root cause of $\mathrm{NC}$ of this profile may be easily identified at individual machines. Reducing scrap is rewarded with profit improvement.
Another benefit is reducing the likelihood of delivering severe NCs to customers.

After setting some generic NC profiles one can match the shapes with all identified NCs to quickly identify NCs with such profiles. The authors detected NCs that match a generic profile as one can see in Figures 14 and 15 . The shape mostly matches with the one outlined in Figure 13(c) and the interpretation can be done as previously described.

Figure 15(a) and (b) depict the shape profile of NC 33 and NC 34, which are also the NCs prevalently identified by the strategies in Section 4.5.1 and 4.5.2. The shapes have similarities with the generic profile shape of Figure 13(d). While NC 33 is less severe it is barely detectable and customer complaints are captured. It has a very low frequency of occurrences but appears very concentrated to single machines. Every time it does appear it is scrapped. NC34 is very severe but detectable. It appears very rarely, not as concentrated as NC 33 and is occasionally recoverable instead of being scrapped.

\section{Conclusion}

On the path of striving for increasing customer satisfaction, TQM is a versatile companion. Successfully proven tools and techniques are great levers to improve quality. But, different industries with different products and processes are of different natures targeted to serve different customer needs. Thus, generic tools and techniques do often not cope and new solutions must be tailored. This is especially true for a complex product in mass production with high customer needs, massive data availability and $100 \%$ final inspection. If the nonconforming quality level is composed of numerous individual NCs, it is of importance to identify the most critical ones for future improvement projects.

The NC Tracking and Prioritisation Matrix approach can be viewed as a contribution to TQM. The approach serves a clear function: prioritising $\mathrm{NCs}$ by selective tracking to identify the most interesting ones for future improvement projects. Hereby, the user must firstly define and group relevant attributes. For those attributes 
data must be gathered, treated and scaled. By setting weights to the individual attributes, one can level the importance given to the attributes depending on one's preferences. In addition to the methodology, an application case from the automotive industry is provided. Its results could demonstrate the identification of critical NCs among a numerous set. As attributes, elements of FMEA and other quality relevant data were chosen. Different weight setting strategies resulted in different identified NCs of which some were prevalently showing.

Strong points of the method are its great visualisation and modular composition of attributes. The $2 \times 2$ matrix eases the presentation of results for highlighting the importance and for engaging management in order to set basis of a successful improvement project. The approach is highly flexible because the priorities given can be changed to retrieve different results. The NCs are changing their positions within the matrix and based on their weightings the areas 'critical', 'to be observed' and 'controlled' are filled with different NCs and are imposing themselves or not for future improvement projects. Furthermore, the multi-attributes on each axis can be easily composed differently if more attributes are identified as relevant or existing ones assessed to be not contributing anymore.

Future research could be directed towards identifying the validity of the approach in different environments other than the one described in the application case of this paper. Additionally, improving the effectiveness of the approach from the perspective of the user can be investigated. For instance one must consider updating the input of attributes or redoing the evaluation of qualitative data over time. Also worth considering is the integration to the IT system of a company to comfortably treat and input quantitative data.

\section{Acknowledgements}

Furthermore, the support and cooperation of the managers and staff of the company, which remains to be anonymous, in the application case is highly appreciated.

\section{Funding}

The authors acknowledge the support of Fundação para a Ciência e a Tecnologia (FCT) [grant number SFRH/BD/33791/ 2009].

\section{Notes on contributors}

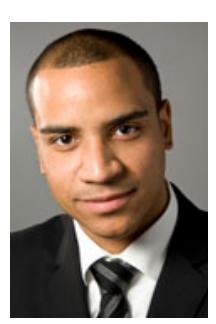

Michael Donauer is a $\mathrm{PhD}$ candidate at the University of Porto within the MIT Portugal Program, an international collaboration. His research interests are in the field of testing and inspection strategies, simulation of manufacturing lines and cost modelling. Prior to joining the $\mathrm{PhD}$ program he graduated from the Karlsruhe Institute of Technology (KIT) holding the equivalence to a Master's degree in Business Engineering. During his studies he gained theoretical and practical experiences in four continents through studying abroad and working for automotive and management consulting companies.

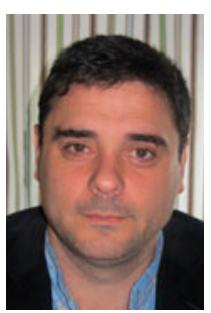

Paulo Peças has a doctorate in Mechanical Engineering at Instituto Superior Técnico (Technical University of Lisbon). $\mathrm{He}$ is an assistant professor at IST in the Manufacturing Technologies \& Industrial Management scientific area. During the last 10 years he has participated and integrated coordination teams of R\&D projects at both national and European levels. The research activity has focused on the development of models to support decision-making, comparative analysis and best-practices implementation in the scope of Life Cycle Engineering and lean \& agile manufacturing. He has a large number of scientific and technical publications in national and international conferences and journals.

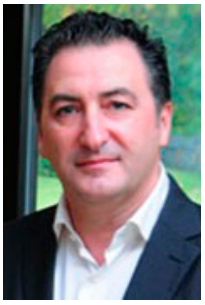

Americo Azevedo is an associate professor in Department of Industrial Engineering and Management at Faculty of Engineering of University of Porto. He holds a $\mathrm{PhD}$ from University of Porto. His research and teaching focuses on operations management, business processes management and enterprise collaborative networks.

$\mathrm{He}$ is a registered professional engineer and a research manager at Inesc Tec (private applied research Institute - formerly Inesc Porto). He has been author of many articles in international journals and technical publications and also active in preparing and participating in $\mathrm{R} \& \mathrm{D}$ projects involving industrial companies. He has been reviewer and evaluator of several international R\&D Industrial projects and member of several scientific programmes committees.

\section{References}

Ahire, S. L., and D. S. Rana. 1995. "Selection of TQM Pilot Projects Using an MCDM Approach." International Journal of Quality \& Reliability Management 12 (1): 61-81.

Ahmed, S., and M. Hassan. 2003. "Survey and Case Investigations on Application of Quality Management Tools and Techniques in SMIs." International Journal of Quality \& Reliability Management 20 (6/7): 795-826.

ANSI, ISO, ASQC A3534. 1993. Statistics - Vocabulary and Symbols, Part II: Statistical Quality Control. MilwaukeeWI: American Society for Quality.

Antony, J., E. V. Gijo, and S. J. Childe. 2012. "Case Study in Six Sigma Methodology: Manufacturing Quality Improvement and Guidance for Managers." Production Planning \& Control 23 (8): 624-640.

Beckman, S., and D. Rosenfield. 2007. Operations Strategy: Competing in the 21st Century. McGraw-Hill/Irwin.

Bilgen, B., and M. Şen. 2011. "Project Selection through Fuzzy Analytic Hierarchy Process and a Case Study on Six Sigma Implementation in an Automotive Industry." Production Planning \& Control 23 (1): 2-25. 
Boran, S., H. R. Yazgan, and K. Goztepe. 2011. “A Fuzzy ANP-Based Approach for Prioritising Projects: A Six Sigma Case Study." International Journal of Six Sigma and Competitive Advantage 6 (3): 133-155.

Bounds, G. M. 1994. Beyond Total Quality Management. Toward the Emerging Paradigm. New York: McGraw-Hill.

Büyüközkan, G., and D. Öztürkcan. 2010. "An Integrated Analytic Approach for Six Sigma Project Selection.” Expert Systems with Applications 37 (8): 5835-5847.

Dale, B. G., and R. McQuater. 1998. Managing Business Improvement and Quality: Implementing Key Tools and Techniques. Oxford: Blackwell Business.

Deming, W. E. 1986. Out of the Crisis. Cambridge: Massachusetts Institute of Technology, Center for Advanced Engineering Study.

Deming, W. E. 2000. The New Economics: For Industry, Government, Education. The MIT Press.

Freiesleben, J. 2004. "On the Limited Value of Cost of Quality Models." Total Quality Management \& Business Excellence 15 (7): 959-969.

Gowen III, C. R., G. N. Stock, and K. L. McFadden. 2008. "Simultaneous Implementation of Six Sigma and Knowledge Management in Hospitals." International Journal of Production Research 46 (23): 6781-6795.

Hellsten, U., and B. Klefsjö. 2000. "TQM as a Management System Consisting of Values, Techniques and Tools." The TQM Magazine 12 (4): 238-244.

Henderson, B. 1973. "The Experience Curve Reviewed: IV the Growth Share Matrix or the Product Portfolio." $B C G$ Perspectives, 135.

Hirschman, A. O. 1964. "The Paternity of an Index." American Economic Review 54: 761-762.

Hradesky, J. L. 1995. Total Quality Management Handbook. New York: McGraw-Hill.

Hu, G., L. Wang, S. Fetch, and B. Bidanda. 2008. "A MultiObjective Model for Project Portfolio Selection to Implement Lean and Six Sigma Concepts." International Journal of Production Research 46 (23): 6611-6625.

Ishikawa, K. 1976. Guide to Quality Control. Tokyo: Asian Productivity Organization.

Ishikawa, K. 1990. Introduction to Quality Control. Productivity Press.

Juran, J. M., and A. B. Godfrey. 1999. Juran's Quality Handbook. 5th ed. New York: McGraw-Hill.

Juran, J. M., and F. M. Gyrna Jr. 1980. Quality Planning and Analysis. 2nd ed. New York: McGraw-Hill.

Kumar, M., J. Antony, and B. R. Cho. 2009. "Project Selection and Its Impact on the Successful Deployment of Six Sigma." Business Process Management Journal 15 (5): 669-686.

Lakhe, R. R., and R. P. Mohanty. 1994. "Understanding TQM." Production Planning \& Control 5 (5): 426-441.

Lowy, A., and P. Hood. 2004. The Power of the 2 X 2 Matrix: Using 2 X 2 Thinking to Solve Business Problems and Make Better Decisions. San Francisco, CA: Jossey Bass, A Wiley Imprint.

McDermott, R. E., R. J. Mikulak, and M. R. Beauregard. 1996. The Basics of FMEA. Portland: Productivity.
McQuater, R. E., C. H. Scurr, B. G. Dale, and P. G. Hillman. 1995. "Using Quality Tools and Techniques Successfully." The TQM Magazine 7 (6): 37-42.

Mizuno, S. 1988. Management for Quality Improvement: The 7 New QC Tools. Cambridge, MA: Productivity Press.

Morrison, A., and R. Wensley. 1991. "Boxing up or Boxed in? A Short History of the Boston Consulting Group Share/ Growth Matrix." Journal of Marketing Management 7 (2): 105-129.

Oakland, J. S. 2008. Statistical Process Control. 6th ed. Oxford: Butterworth-Heinemann.

Ōno, T. 1988. Toyota Production System: Beyond Large Scale Production. Cambridge, MA: Productivitiy Pres.

Plunkett, J. J., and B. G. Dale. 1987. "A Review of the Literature on Quality-RELATED Costs." International Journal of Quality \& Reliability Management 4 (1): 40-52.

Rampey, J., and H. V. Roberts. 1992. Perspectives on Total Quality. Proceedings of Total Quality Forum IV. Cincinnati, $\mathrm{OH}$.

Rhoades, S. A. 1993. "The Herfindahl-Hirschman Index. (Cover Story)." Federal Reserve Bulletin 79 (3): 188-189.

Saaty, T. L. 1980. The Analytic Hierarchy Process. New York: McGraw-Hill.

Schiffauerova, A., and V. Thomson. 2006. "A Review of Research on Cost of Quality Models and Best Practices." International Journal of Quality \& Reliability Management 23 (6): 647-669.

Shah, R., A. Chandrasekaran, and K. Linderman. 2008. "In Pursuit of Implementation Patterns: The Context of Lean and Six Sigma." International Journal of Production Research 46 (23): 6679-6699.

Shewhart, W. A. 1931. Economic Control of Quality of Manufactured Product. New York, 501.

Shingō, S. 1986. Zero Quality Control: Source Inspection and the Poka-Yoke System. Productivity Press.

Singh, R. K., S. Kumar, A. K. Choudhury, and M. K. Tiwari. 2006. "Lean Tool Selection in a Die Casting Unit: A FuzzyBased Decision Support Heuristic." International Journal of Production Research 44 (7): 1399-1429.

Taguchi, G. 1986. Introduction to Quality Engineering: Designing Quality into Products and Processes.

Van de Water, H., and J. d. Vries. 2006. "Choosing a Quality Improvement Project Using the Analytic Hierarchy Process." International Journal of Quality \& Reliability Management 23 (4): 409-425.

Womack, J. P., D. T. Jones, and D. Roos. 1990. The Machine That Changed the World: Based on the Massachusetts Institute of Technology 5-Million Dollar 5-Year Study on the Future of the Automobile. Cambridge, MA: Massachusetts Institute of Technology Rawson Associates. (Free Press paperbacks).

Wong, W. P., J. Ignatius, and K. L. Soh. 2012. "What is the Leanness Level of Your Organisation in Lean Transformation Implementation? An Integrated Lean Index Using ANP Approach." Production Planning \& Control 25 (4): 273-287. 


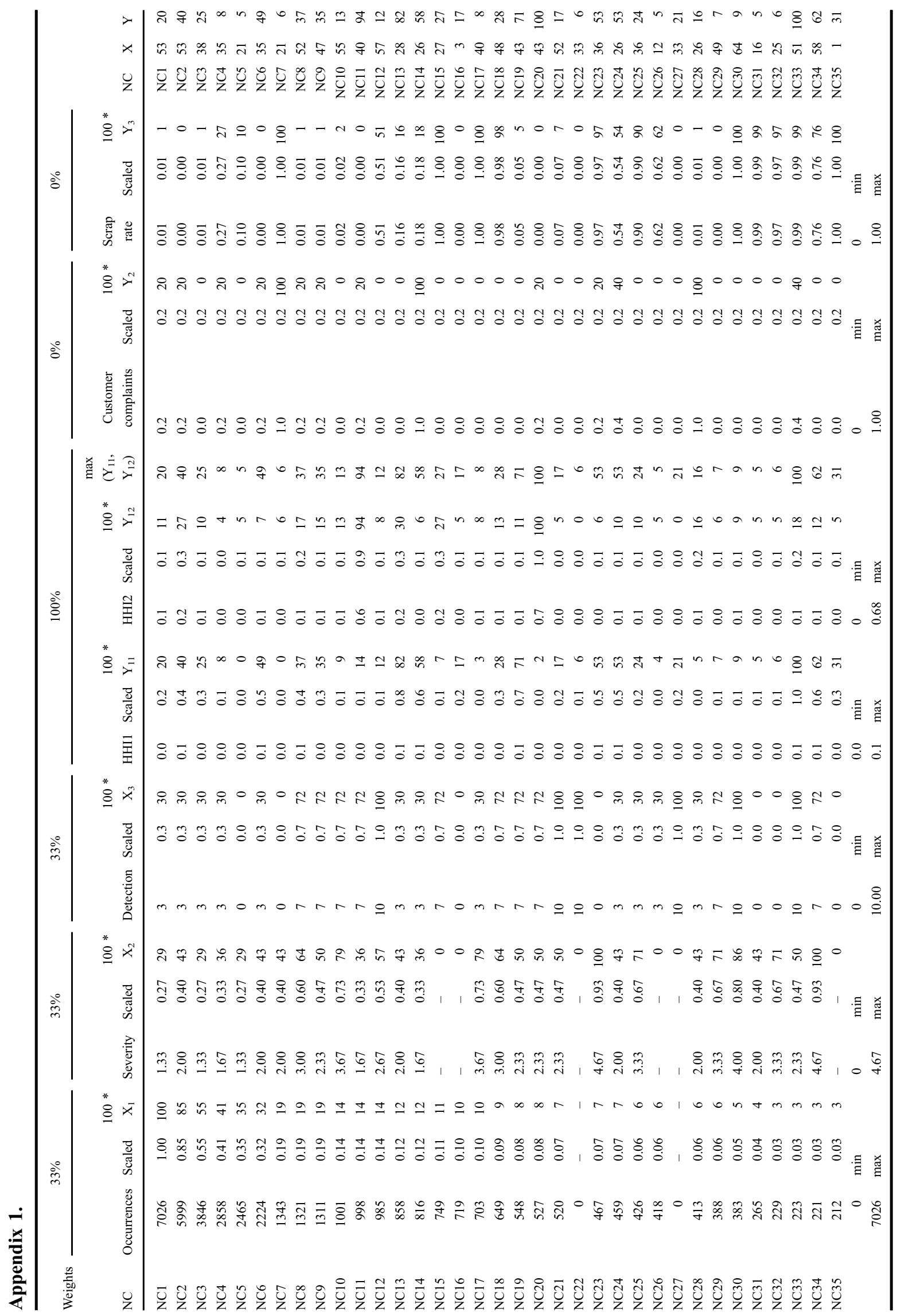

